\title{
Essential Steps for Algerian Researcher to Target ISI Journals
}

\author{
Tayeb Aissaoui \\ ${ }^{1}$ Department of Chemical Engineering, Université Ferhat Abbas, Sétif-1, 19000 Sétif, Algeria
}

\begin{abstract}
One of the most potent factors widely used in judging the quality of academic institutions is publication. High impact journals are targeted by scientific research groups around the globe by improving the quality of their work. Clearly, researchers perform investigations to address scientific, economic and even political institutions through writing and publishing. Mastering the skills and mechanism of writing scientific article from idea to publication is highly required especially for universities that witness poor research performance. Algerian universities are among the academic institutions that attempt to reach the goal of publishing in high impact journals. This article comes to encourage Algerian researchers to target high quality journals and highlights the necessary steps toward achieving this target. In this paper, the performance of Algerian scientific community was discussed. The importance of publication by answering some essential questions was reported. Moreover, the definition of Impact Factor (IF), Institute for Scientific Information (ISI) and Journal Citation Report (JCR) were stated. Additionally, skills of writing a scientific article and submission process were highlighted. At the early stage of this research, there were few research papers available in the literature dealing and analyzing scientific research activities in Algeria. Further investigations and practical activities such as workshops on how to write scientific article are highly recommended. This paper targets in particular science and engineering researchers. However, other researchers could benefit from it general ideas.
\end{abstract}

Keywords: Algerian universities; Algerian academic institutions; scientific research, publication, ISI, Impact factor

\section{Introduction}

Science is the result of much extraordinary effort by researchers, attempting to learn how nature works (Valiela 2001). Conducting scientific research is designed for earlycareer researchers in the sciences: those who aim to improve their skills for performing research more efficiently and successfully, and those who are new to write their research outcomes as a manuscript for submission to an international refereed journal (O'Connor 2009). Research begins by asking questions then attempting to answer these questions in a descriptive and detailed manner. Providing results to confirm the answer is also an essential step of the research process. In addition, sharing research findings is an important part of the process of scientific research (Derntl 2014).

All scientists face pressure and obstacles to publish their results in prestigious journals and all face challenges when trying to write and share their work through publication (O'Connor 2009). Performing high-quality research produces high-quality scientific article (El-Omar 2014). The attentiveness of the scientific audience treats journals differently. Clearly, papers that are often cited score better than others (Taborsky 2007).

In scientific publishing, one measure has developed into a universal remedy (Taborsky 2007). Impact factor (IF) of scientific journals has gained importance, in scientific work, research management or policy and scientific information management (Moed and Van Leeuwen 1995). In this context, it is to be noted that the IF is calculated by the Institute for Scientific Information (ISI) and published in Journal Citation Reports (JCR) (T. N. van Leeuwen 1999). The ISI publishes annually listings of IFs of scientific journals, based upon the Science Citation Index (SCI) data (Moed and Van Leeuwen 1995). The JCR compiled from scientific literature in the ISI database by Thomson Scientific provide a shorthand measure of scientific success (Taborsky 2007).

Research groups around the globe are targeting high-impact journals by improving their research quality. This mentality has created an academic competition among researchers, who will reach the higher impact factor!?. It should be mentioned that Algerian academic institutions such as universities, institutions and research centers have not been classified in good rank in terms of international scale, and this is due to the quality of Algerian academic institutions' research. Publishing in high-impact journals allows universities to be ranked in good international scale. It is not to generalize the negative situation of scientific research activities and achievements in Algeria in terms of publication output in high-impact journals. Many individual efforts have been devoted by bright Algerian scholars and many publications performed by Algerian researchers were published in ISI journals. However, keeping silent on the weak performance of the Algerian academic community is not in its interest. Serious challenge should be raised when we witness an Algerian academic lecturer with 15 years of experience and without any publication (Aissaoui 2016). It is a serious challenge when I asked an Algerian $\mathrm{PhD}$ student coming from Algeria to Malaysia: do you have publications?, and he answered: what is publication? (Aissaoui 2014). It is also a challenge when a $\mathrm{PhD}$ student in her final year asked about the types of an article? (Aissaoui 2016). The above mentioned challenges are to profoundly understand the crisis that Algerian scientific community faces.

This article comes to encourage Algerian young researchers to perform scientific research in a correct way. It is also to highlight the methodology and process to target high-impact journals, precisely ISI journals. The performance of Algerian scientific community was discussed. In addition, the 


\section{International Journal of Science and Research (IJSR) \\ ISSN (Online): 2319-7064}

Index Copernicus Value (2015): 78.96 Impact Factor (2015): 6.391

importance of publication by answering some essential questions was reported. Moreover, high-quality journals such as ISI journals, IF and JCR were discussed. Additionally, skills for writing high-quality manuscript and manuscript submission were highlighted in this work. Further works such as practical workshops on the skills and mechanism of scientific research are important to be addressed with performance to the Algerian academic community.

\section{Algerian Scientific Community Publication}

During the two first decades after independence, scientific research in Algeria was facing a conflict between professionalization autonomy on the one side, and institutionalization control on the other (Hocine 2004). Hocine Khelfaoui (2004) has reported that in early stages of the emergence of Algerian scientific community, the process of professionalization led to greater independence for researchers, which came into conflict with the government control over the process of institutionalization (Hocine 2004). Khelfaoui has also implied that the relationship between scientific and political worlds comprises political backdrop (Hocine 2004). From the very beginning of the history of Algerian scientific community, its mission, vision and objectives were distorted by political backdrop. The first challenge Algerian scientific community faced during its birth was that policy founded scientific research not vice versa. This profound and historical conflict was the cause of the weak level and rank of Algerian scientific research institutions.

In 2010, Roland Waast has reported that after independence, Algeria focused on primary and secondary education. However, after 1975 Algerian government promoted vigorously a scientific option (Waast 2010). Roland Waast said:

'A number of polytechnics were opened, universities of S\&T created, enrolment grew quickly and a national body for driving research (ONRS) was granted a large budget. These efforts were due to the weight in the government of a faction of 'technocrats', who tried to launch heavy industrialization of the country to make it independent and prepare for the post-petroleum era (Waast 2010)'.

Furthermore, Khelfaoui (2004) illustrates that the first attempts to organize research in Algeria was in 1970, with the establishment of the Ministry of Higher Education and Scientific Research (MESRS), then by the Provisional Council for Scientific Research (CPRS) in 1971, followed by the National Office for Scientific Research (ONRS) in 1973 (Hocine 2004). Besides, the French National Scientific Research Council (CNRS) in 1977stated the existence of research centers set up between 1965 and 1976 (Hocine 2004).

It should be noted that the period between the independence in 1962 and civil war in 1992 was not sufficient to overcome the obstacles and establish strong scientific community and institutions. During the civil war, the interest of the disturbed government was focusing on bringing back peace and security. Therefore, the ten years of war did not witness any developments in terms of scientific research. After the civil war and by the coming of the president Abdelaziz Bouteflika in 1999, scientific research in Algeria witnessed a quantitative and not qualitative improvement. Universities are all over Algeria, new research centers were founded and research budgets have been increased comparing with previous budgets. But these developments in the sector of academic and scientific institutions lack of qualitative essence of scientific research which is producing articles, patents, research project and so on and so forth. It is not to deny some academic achievements by Algerian scientific institutions, but the general image is that Algerian universities suffer from ranking among the weakest universities in the world. For instance, the best Algerian university which is Université des Sciences et de la Technologie Houari Boumediene, Algiers ranks 2099 in world rank, followed by Université Abou Bekr Belkaid, Tlemcen which ranks 2213, then Université Djillali Liabes, Sidi-Bel-Abbès which ranks 2675 (Data from Ranking Web of Universities) (2016).

Publications have a profound impact on the international rank of universities, and the above classification of the best Algerian universities compared with international universities is clear and regrettable evidence that significant percentage of Algerian lecturers, researchers and research students do not publish neither in simple nor in high-impact journals Table 1 and figure 1 demonstrate the classification of the ten best Algerian universities in international scale.

Table 1: Ten Algerian universities rank from ranking web of universities for the year 2016 (Data from Ranking Web of

Universities).

\begin{tabular}{|c|c|c|}
\hline $\begin{array}{c}\text { Country } \\
\text { rank }\end{array}$ & $\begin{array}{c}\text { World } \\
\text { rank }\end{array}$ & University name \\
\hline 1 & 2099 & $\begin{array}{c}\text { Université des Sciences et de la Technologie } \\
\text { Houari Boumediene }\end{array}$ \\
\hline 2 & 2213 & Université Abou Bekr Belkaid Tlemcen \\
\hline 3 & 2675 & Université Djillali Liabes \\
\hline 4 & 2691 & Université Mohamed Khider Biskra \\
\hline 5 & 2716 & Université de Bejaia \\
\hline 6 & 2894 & Université d'Alger 1 \\
\hline 7 & 3068 & École Nationale Polytechnique d'Alger \\
\hline 8 & 3088 & Université Constantine 1 (Ex Université \\
Mentouri)
\end{tabular}

Clearly, table 1 illustrates that Université des Sciences et de la Technologie Houari Boumediene was classified as the best Algerian university in the year 2016, followed by Université Abou Bekr Belkaid Tlemcen, then Université Djillali Liabes in the third place. After that Université Mohamed Khider Biskra in the fourth place. However, table 1 also shows that the best Algerian university in the international scale is considered as a weak university. Université des Sciences et de la Technologie Houari Boumediene ranks 2099 in world rank, and the tenth best Algerian university ranks 3139 in world rank. 


\section{International Journal of Science and Research (IJSR) \\ ISSN (Online): 2319-7064}

Index Copernicus Value (2015): 78.96 | Impact Factor (2015): 6.391

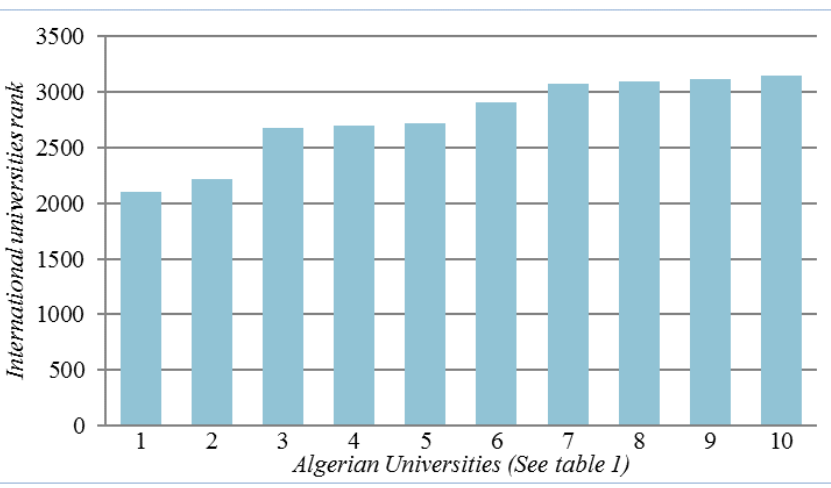

Figure 1: The ten best Algerian universities, local and international rank in the year 2016 (Data from Ranking Web of Universities)

The question of the weak performance of the Algerian scientific research community and institutions would not be answered without being deeply aware of the causes and responsible for this crisis. Some argue that due to the policy of the previous and current government, scientific research in Algeria faces the mentioned challenges and obstacles. While others state that lecturers, researchers and academic staffs should be also involved and understand their part of causing the crisis. Investigations are needed to resolve this issue and correctly understand the cause of this crisis. However, it is our duty as Algerian researchers to be involved in resolving the problem and honestly answer this critical question. Who is the responsible for the weak performance of the Algerian academic institutions!?.

\section{Essential questions before to publish}

\subsection{What is publication?}

The dissemination of research findings is an integral part of the research process (Derntl 2014). Scientific article is a written and published report describing original research results (Day 1983). Researchers write to keep records of their work for themselves. Also, for readers and peers who are expecting a standard form, language and style when reading research papers (Derntl 2014). Publication is to share your research outcomes through international journals and to keep the international scientific community updated with the recent findings in your research field.

\subsection{Why do we publish?}

The reason why researchers conduct research and publish papers differs from one researcher to another. A particular case of master and $\mathrm{PhD}$ students should be highlighted when they intend to publish just to complete their graduation requirements. Publication for this reason is accepted but limiting students target in their study life will not encourage them to further their research and become future researchers. A student in her final $\mathrm{PhD}$ year in one of the Algerian universities could be a good example when we deal with the reason why researchers or student researchers publish in Algeria. The student asked me a question during my presentation in a workshop on the skills and mechanism of writing scientific article. The question was: what are the types of papers in scientific research?. It is good to ask questions, any kind of questions. However, $\mathrm{PhD}$ student that is about to graduate should have two articles published in ISI journals in some of Malaysian universities for instance, and the reason that made this student think to publish is that she was afraid of not being able to graduate. Personally, publication is a skill that we need to master, it is part of the academic personality that we should gain, and it is also a culture in terms of civilizational aspect. Publication has also humanitarian essence when we contribute in resolving serious world issues such as diseases, civil wars and helping mankind to develop lifestyle. Additionally, the most important scientific reason motivates researchers to publish is to perform investigations to be updated with their research field. Moreover, researcher's curriculum vitae $(\mathrm{CV})$ becomes more attractive by publications.

\subsection{Where to publish?}

Writing scientific article passes through several steps. It starts by raising the issue or the idea that the paper will target and deal with, and ends by submission and dealing with editors' and reviewers' comments. It is to be noted that among the factors that guide the corresponding author to select the journal that their manuscript will be submitted to, are journal's scope and quality. The scope of a journal differs based on the research field of researchers. Chemical, civil, pharmaceutical and electrical engineering, medicine, ecology, social sciences and many other fields are the areas where researchers can determine their scopes based on. Clearly, researcher who investigates $\mathrm{CO}_{2}$ capture technologies and natural gas dehydration for instance, should submit his manuscript to chemical engineering or natural gas journals and not social science journals (Aissaoui, AlNashef et al. 2016). Furthermore, high-quality manuscript should be submitted to a good journal and the quality of the journal is determined by the IF. The higher the IF, the better the journal quality (Taborsky 2007). In this article, ISI journals were selected as high-quality international journals and the process of publishing in these journals was illustrated in the coming sections.

\section{High-Quality Journals}

The higher the IF, the better the journal quality

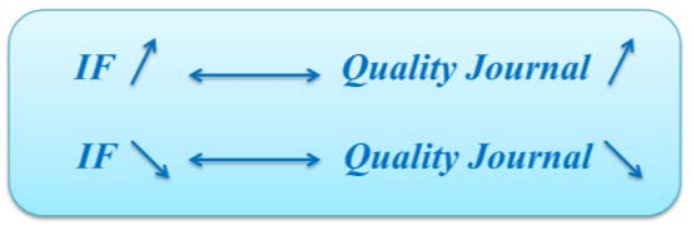

\subsection{Impact factor}

The measure that has come to be used by the scientific community to judge a journal's quality is the impact factor (Taborsky 2007). It simply divides the number of citations in year 3 to those articles published in the respective journal in the preceding years 1 and 2 by the total number of papers published by the journal in years 1 and 2 (Taborsky 2007). This calculation allows comparison of different journals in

\section{Volume 6 Issue 1, January 2017




\section{International Journal of Science and Research (IJSR) \\ ISSN (Online): 2319-7064 \\ Index Copernicus Value (2015): 78.96 | Impact Factor (2015): 6.391}

terms of their attraction to be cited. A higher impact factor means that manuscripts published therein receive on average more attention (Taborsky 2007). The performance of a journal is indicated by the IF which is determined by scientific publishers. Scientists increasingly evaluate and redirect their publication strategies on the basis of a comparative analysis of journal IF (Moed and Van Leeuwen 1995). Librarians use IF as tools for the management of their journal collections (Moed and Van Leeuwen 1995).

$$
I F=\frac{\text { Number of recent item citations }}{\text { Number of recent publications }}
$$

\subsection{Institute for Scientific Information (ISI)}

In 1960, Eugene Garfield founded the institute for scientific information (ISI). After that, in 1992 Thomson Scientific and Healthcare acquired this institute (Online 1992). Decades later, ISI became a part of the intellectual property and science business of Thomson Reuters. I should be noted that Thomson Reuters was established by the combination of two companies which are Thomson Corporation and Reuters in 2007 (2016. Retrieved 2016-09-27). Thomson Reuters Corporation is a provider of news and information for professional markets. One of the business units Thomson Reuters operates through is Intellectual Property \& Science, which provides scientific information and intellectual property, decision support tools and services for governments, academia, publishers, corporations and law firms to protect, commercialize and discover new ideas and brands (Reuters 2016. Retrieved 2016-09-28).

The mission of ISI is to maintain a database of world-wide scholarly content that helps researchers find the highest quality literature relevant to their work (McVeigh 2004). Moreover, ISI database collects information about how often a publication was cited, which is an indication to how often it was read and deemed useful (Taborsky 2007). It is an objective measure to separate the wheat from the chaff! (Taborsky 2007). Additionally, ISI is important tool for measuring the scientific performance of universities, faculties, institutes, and individual authors (STEGMANN 1999).

In order for Algerian scientific institutions to be ranked among the top universities around the world, it is mandatory to target ISI and other high-quality journals. Unfortunately, significant percentage of Algerian students and $\mathrm{PhD}$ holders do not even know what is ISI journal. However, part of this serious challenge could be resolved by performing practical workshops in Algerian scientific institutions and help researchers to master the skills of research and publication, workshops will also make researchers aware and in touch with the international scientific community.

\subsection{Journal citation report (JCR)}

Journal Citation Report displays a systematic, objective means to critically evaluate the high quality journals, with statistical, quantifiable information based on citation data (Reuters 2016). By compiling articles' cited references, JCR helps to calculate research impact at the journal and category levels, and shows the relationship between citing and cited journals (Reuters 2016). Researchers could use JCR to select the journal that fits their scope and manuscript quality. Every year ISI publishes its annual JCR to make researchers aware about the evaluation of the top international journals.

\section{Skills for writing high-quality manuscript}

\subsection{How to start?}

Neoteric idea is the key to successful research projects. Researcher should not repeat what others have already investigated. It is quite important before starting a research project, paper, thesis or any kind of research to carefully select the research topic. Additionally, research projects which investigate current events and challenges are more welcomed by the international scientific community than those projects which do not deal with current and urgent issues. Investigations on cancer, global warming, $\mathrm{CO} 2$ emission, international economic crisis, Syrian civil war and other current and urgent topics gain significant interest and welcome by international scientific community.

Furthermore, one of the important points researcher need to cover when starting a research is to select his research supervisor and team. It has to be said that failing in choosing a good team leads you to face negative experiences. Researchers may steal your idea and performed work and deal with them as their own efforts. Many cases have been registered where researchers were victims of their supervisors and team.

In Algeria, researcher should take into consideration projects fund, equipment availability, the support of research project manager to the research or idea and many other issues which may profoundly impact his research performance, time and quality. For instance, and by experience, it is hard for a chemical engineering researcher to conduct high quality experimental research due to the lack of equipment, chemicals and support. In this case, it is suggested to perform theoretical and computational investigations to avoid the mentioned challenges.

It is also recommended for Algerian researcher when starting a research to think of establishing collaborations with researchers from other international scientific research institutions. This will resolve some challenges such as the lack of equipment, products, even financial support and many other challenges.

Collecting data is the first practical action many researchers start with. However, it should be noted that datum collects itself and every datum we found leads to other data. It is not advised to focus just on collecting data and spending a lot of time doing that. Reading articles helps to discover more concentrated articles and so on and so forth. Additionally, before starting a research, it is also important to read the guide for authors provided by the journal that you aim to

\section{Volume 6 Issue 1, January 2017}




\section{International Journal of Science and Research (IJSR) \\ ISSN (Online): 2319-7064 \\ Index Copernicus Value (2015): 78.96 | Impact Factor (2015): 6.391}

submit your manuscript to. The guide for authors provides the methodology, policy and strategy of the journal.

\subsection{Title page (Title, Affiliation, Abstract and keywords)}

Title of high-quality manuscript is concise and informative. Avoiding abbreviations and formula in titles is essential (Elsevier, 2009). In addition, long titles are not recommended in high-quality papers. Title should cover the subject of the article; it also needs to be clear using academic words. In manuscript writing, after the title, names of the coauthors followed by their affiliations are listed to describe the address of the co-authors. Having bright names in your article make it more attractive for readers and give it high value and interest. Moreover, the co-author who handles correspondence at all stages of refereeing and publication, also post-publication should be determined with telephone and fax numbers in addition to the e-mail address and the complete postal address (Elsevier, 2009).

The abstract summarizes the problem or objective, method, results, and conclusions of the article in 200 words (elsevier.com/authors 2016). It should be able to fully represent the paper. Moreover, it is suggested to write the abstract last to reflect the content of the article accurately (elsevier.com/authors 2016). Abstract doesn't include references, figures or tables (elsevier.com/authors 2016). The audience attempt to discover the content of the article by firstly reading the title and abstract. Therefore, an accurate, clear, detailed and informative abstract will attract readers to go into the profound details of the article.

Keywords are important words that, along with those in the title, capture the research effectively. Additionally, they are used by abstracting and indexing services; therefore, choosing the attractive ones can increase the chances of the article being found by other researchers (elsevier.com/authors 2016). The number of the keywords is mostly limited by six words for most of the journals.

\subsection{Introduction}

In the introduction, authors should explain why they have undertaken their particular topic, what they aimed to achieve with it, and how this constitutes a useful addition to the existing body of evidence on this subject (Ecarnot, Seronde et al. 2015). The purpose of the introduction is to give the readers the important information to understand why researchers conduct the study and to state the research question (Cals and Kotz 2013). The structure of an introduction can be visualized as a funnel. The broadest part at the beginning represents the general context of the study subject. It then specifies more topical contextual information. Finally, it ends with the specific rationale of the study and, vitally, the aim, purpose, or objective (Cals and Kotz 2013). It is advised to start the introduction by giving a general idea about the subject then moving into the depth of the topic step by step. For instance, if you are investigating novel $\mathrm{CO} 2$ capture technique, you may start the introduction by describing global warming issue and its impact to the atmosphere, after that you move to the emission of $\mathrm{CO} 2$ by several sources then you illustrate the different technologies reported in the literature dealing with the issue. Furthermore, you mention the drawbacks of the previous techniques and how the proposed technique could be their alternative. Successively, you describe the necessary in the study based on the topic you are investigating.

The contributed value of the study should be reported in the introduction (Ecarnot, Seronde et al. 2015). In addition, the introduction should flow to the identification of the gap in knowledge that the authors hope to fill (Ecarnot, Seronde et al. 2015). However, the introduction should allow the readers to understand why the authors set out to perform the investigated study and why the specific aims are what they are. It must not be a full review of the whole field you are researching (Cals and Kotz 2013). Informative, concise and short introduction is preferred by editors, reviewers and readers. In addition, very recent references will enhance the value of the paper. The introduction is an important section in the article. Therefore, it should be well written. The problem, methodology and findings should be illustrated using academic words. Table 2 provides an outline of the main features of the introduction section, with some examples.

Table 2: Outline of the main features of the Introduction section, with examples ( Data from (Ecarnot, Seronde et al.

$$
\text { 2015) with permission). }
$$

\begin{tabular}{|c|c|}
\hline Feature & Example \\
\hline $\begin{array}{l}\text { Background describing what } \\
\text { is known on the subject }\end{array}$ & $\begin{array}{l}\text { Percutaneous coronary } \\
\text { intervention is the cornerstone } \\
\text { of therapy for acute coronary } \\
\text { syndromes, but may be } \\
\text { associated with procedure- } \\
\text { related complications }\end{array}$ \\
\hline $\begin{array}{l}\text { What is not known? What } \\
\text { elements are still subject } \\
\text { to controversy? What is } \\
\text { the exact gap in the } \\
\text { knowledge that your study } \\
\text { hopes to fill? Cite any } \\
\text { existing data, especially } \\
\text { conflicting data that } \\
\text { indicate uncertainty. }\end{array}$ & $\begin{array}{l}\text { It remains unknown whether. . } \\
\text { To date, it has not been proven. } \\
\text {.. } \\
\text { No study to date has } \\
\text { investigated the effect of. . } \\
\text { There are few data to quantify. . } \\
\text { The effect of. . . on. . . remains } \\
\text { unclear }\end{array}$ \\
\hline $\begin{array}{l}\text { Objective (working } \\
\text { hypothesis) }\end{array}$ & $\begin{array}{l}\text { We hypothesized that the } \\
\text { administration of. . . would } \\
\text { reduce/increase. . . in the } \\
\text { context of. . }\end{array}$ \\
\hline $\begin{array}{c}\text { Cite the exact parameter you } \\
\text { plan to measure }\end{array}$ & $\begin{array}{l}\text { We aimed to } \\
\text { identify/assess/evaluate/investi } \\
\text { gate. . }\end{array}$ \\
\hline $\begin{array}{c}\text { Cite the type of patient } \\
\text { population or clinical context }\end{array}$ & $\begin{array}{l}\text { Through a prospective, single- } \\
\text { /multicentre, } \\
\text { observational/interventional. . . } \\
\text { study }\end{array}$ \\
\hline Cite any second & \\
\hline
\end{tabular}

\subsection{Methodology (Materials and Methods or Experimental Methods)}

Methods section should be reported in detail that readers can replicate the research, and assess whether the methods justify 


\section{International Journal of Science and Research (IJSR) \\ ISSN (Online): 2319-7064}

Index Copernicus Value (2015): 78.96 | Impact Factor (2015): 6.391

the conclusions (elsevier.com/authors 2016). In the methods section, all information to understand on how the key findings in the paper were derived should be mentioned. In addition, researcher should explain when and where the study was performed, how the sample was selected, and which inclusion/exclusion criteria were applied (Kotz and Cals 2013). Putting results in methods section should be avoided (Kotz and Cals 2013). Authors should explain how they studied the problem, identify the procedures they followed (elsevier.com/authors 2016). It is also advised for researchers to explain why they made certain methodological choices and why they think these were the best options given the context (Kotz and Cals 2013). Researchers should match the part on data analysis with the research questions. The credibility of the methods by citing previous research could also be demonstrated in the methods section (Kotz and Cals 2013). Moreover, it is advisable to use the past tense rather than the first person, although this will vary from journal to journal (elsevier.com/authors 2016). Kotz and Cals have reported a checklist for the methods section as following (Kotz and Cals 2013):

*Include basic information on study design, setting and subjects, data collection, data analysis, and ethical approval.

*Refer to previous publications from the same large research project, such as a study protocol, for additional information (if applicable)

*Consider providing detailed information on the methods as web only supplementary materials

*Ask yourself, "Would a researcher be able to reproduce the study with the information I provide in this paper?'”

Methodology section should be before the results and discussions sections as it gives the method how researchers found their reported results. The materials, equipment, chemicals or software programs used to conduct the experiments or computational work should be mentioned with their resources such as company and country. Additionally, if the method is new, authors need to explain it in detail or references should be included if the method was already used by other researchers.

\subsection{Results and discussions}

This section is considered as the core of the article. In this part of the article, authors will present in details the results they found. The outcomes should be presented in figures, tables, images, schemes and other formats. Researchers must illustrate their findings in a clear and detailed manner because editors, reviewers and readers deal with this section as the part where the article shows how it contributes to the scientific community. Kotz and Cals have stated a checklist for the results section as following (Kotz and Cals 2013):

* Write the results section in the past tense.

*Structure roughly into: recruitment/response, sample characteristics, primary analyses, secondary analyses, and ancillary analyses.

* Match the results section with the methods section.

*Present findings without interpretation.
*Highlight findings from tables and figures in the text. *Present estimates with $95 \%$ confidence intervals.

*Consider providing additional results in tables and figures as web only supplementary material.

Discussions section is linked with results section. Authors should describe the meaning of their results, especially in the context of what was already reported about the subject (elsevier.com/authors 2016). In addition, comparing the reported results with previous published results will increase the quality of the article. However, researchers should be honest in presenting their outcomes as they may find negative results. Negative results are also important to make other researchers aware about the way they should avoid. Cals and Kotz have also reported the checklist for the discussion section as following (Cals and Kotz 2013):

* Check if the discussion has a clear inverted funnel shape with distinct sections providing:

- A summary of main findings (What did we find?);

- Comparisons with other studies (What is known?, What is new?, and How does this fit in?),

- Strengths and limitations (Are the findings true?

- Implications (Are the findings important? What can we do with them?).

*Answer the research question in the first paragraph and check if this is in line with the research question posed in the introduction (hourglass model).

*Check to see if the discussion section does not present new results.

*Be frank about acknowledging limitations

*Ensure it offers a clear ending to the storyline of the paper (citable statement).

*Formulate a clear and concise one-liner as the bottom line of the paper.

\subsection{Conclusion}

The summary could be written as an independent section or as the last paragraph of the discussion (Shokeir 2014). It should address the most relevant outcomes of the paper. It is the digest of the whole study (Shokeir 2014). The conclusion should not be a repetition of the abstract, but an extended summary. It justifies and explains the conclusion of the study (Shokeir 2014). Authors should avoid references in the conclusion as it concludes the pure results, findings and achievements of the authors. It is advisable to suggest further investigations in the conclusion section to enhance the quality of the paper and indicates that the reported work would be linked with future publications.

\subsection{Acknowledgments}

Acknowledgements should be brief, naming those who helped with authors' research; contributors, or suppliers who provided materials (elsevier.com/authors 2016). Authors should also disclose any kind of conflict of interest, either financial or other substantive conflict that could be seen to influence the results or interpretations of the work conducted (elsevier.com/authors 2016). 


\section{International Journal of Science and Research (IJSR) \\ ISSN (Online): 2319-7064}

Index Copernicus Value (2015): 78.96 Impact Factor (2015): 6.391

\subsection{References}

Any information that isn't 'common knowledge', or generated by authors experiments or findings, must be recognized with a citation; and quoted text should be within quotation marks, and include a reference (elsevier.com/authors 2016). The guide for authors for the targeted journal includes its recognized format of citations and references. Endnote software is used for organizing references in different styles, it saves time, effort and helps to avoid mistakes in ordering and organizing references.

\section{Manuscript Submission}

After completing the manuscript, authors should target the journal that fits the scope of their study. High-quality work leads the authors to target high-quality journal. However, the manuscript should not be submitted to different journals in the same time. There are few steps corresponding author should pass through to submit the manuscript.

Firstly, the corresponding author should open an account in the web page of the journal. In this article the author will illustrate the process of submitting a manuscript to the Journal of Natural Gas Science and Engineering (JNGSE) which is one of ISI journals. Image 1 shows the Login page of the targeted journal. If the author already has an account, he just writes his username and password, otherwise the author needs to open an account by following the instructions given by the website and then he can login as author.

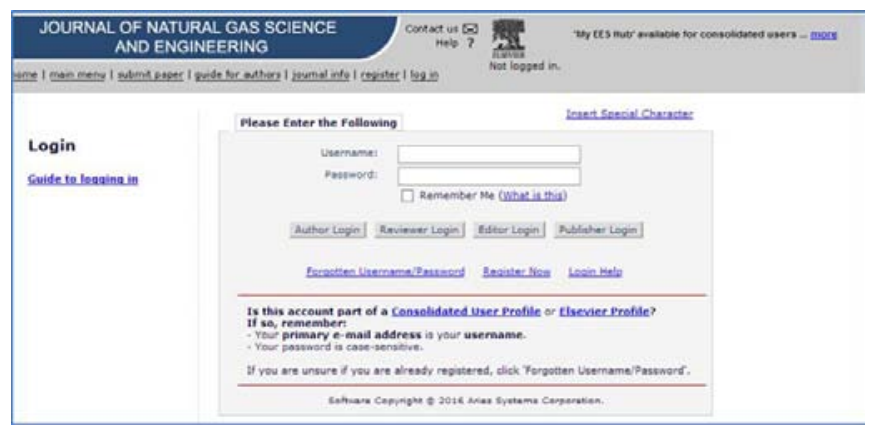

Image 1: Login page of Journal of Natural Gas Science and Engineering (Image from JNGSE web page).

Furthermore, the author will be guided to the page where he can follow the status of his article from submission to final decision. Image 2 illustrates the different steps the manuscript may pass through during its submission. The author goes to "submit new manuscript" to select and choose the type of the article he wrote. Image 3 demonstrates the different types of articles published by the JNGSE. After selecting the type of the article, the author can then start the submission process by writing the title of the article and adding the co-authors then the abstract followed by keywords until the corresponding author reaches the attachment of the files such as manuscript, graphical abstract, tables, figures and other related documents. Image 4 shows the different steps of submission process.

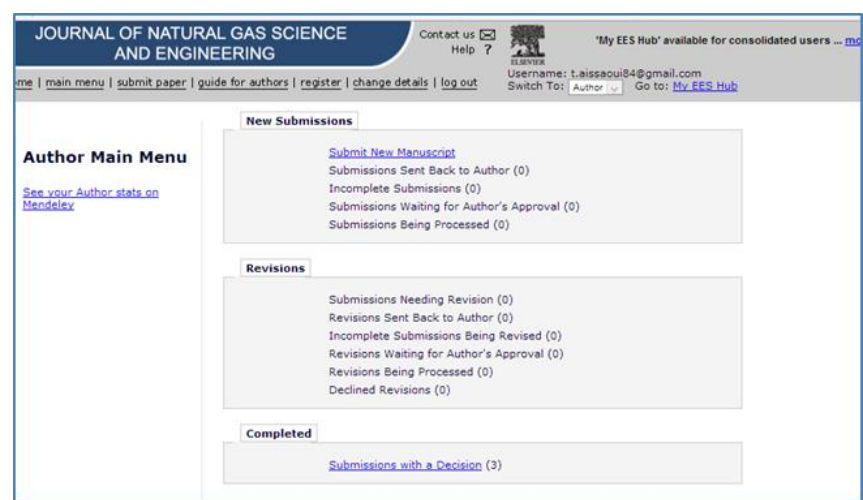

Image 2: Starting the submission to Journal of Natural Gas Science and Engineering (Image from JNGSE web page).

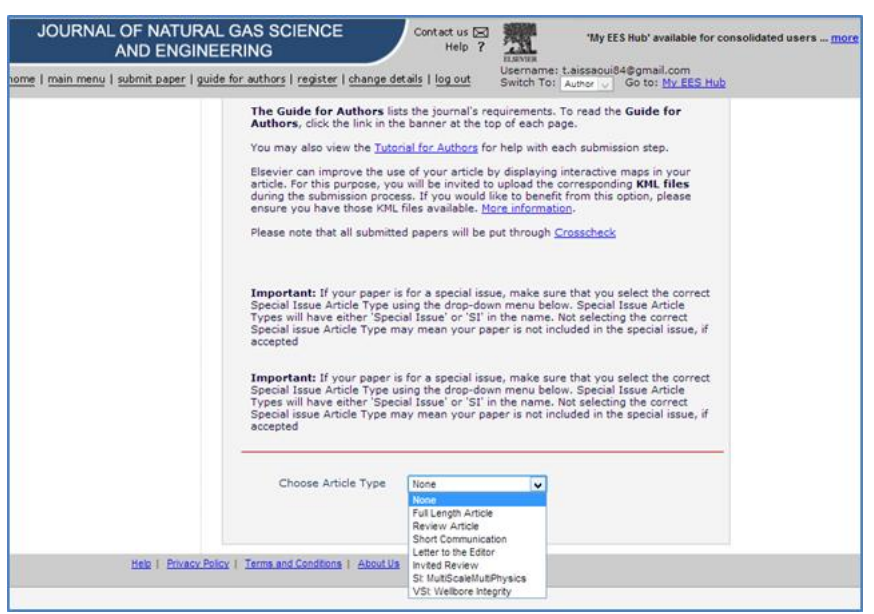

Image 3: Selecting the type of the article at Journal of Natural Gas Science and Engineering (Image from JNGSE web page).

After attaching the required and necessary files, pdf file will be created to the attached documents. The corresponding author should revise the pdf file before to confirm the submission. The manuscript then will be received by the technical committee to revise its language then to the editor to decide whether the manuscript is good in terms of scientific quality, scope of the journal and then the manuscript will be sent to reviewers to judge it. Corrections may be suggested by the editor and reviewers and the corresponding author will be in direct contact with the editor to follow up the status of the article, then the decision will be made "accepted" without correction or "accepted" with minor or major corrections or "rejected".

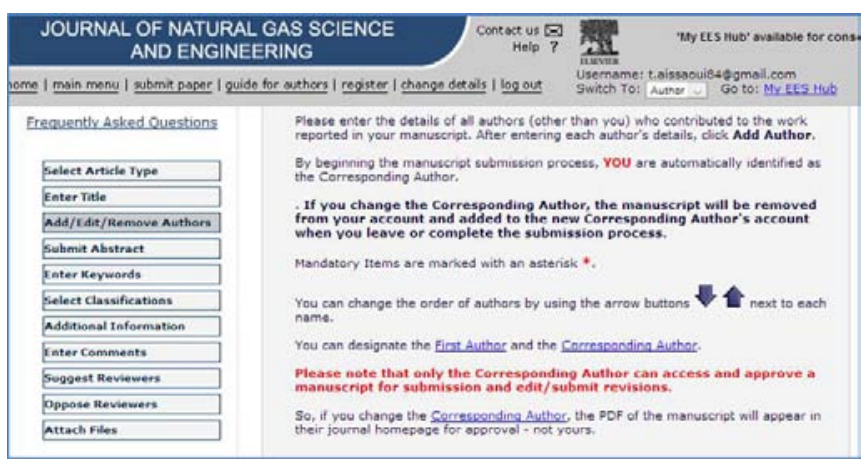

Image 4: Submission process at Journal of Natural Gas Science and Engineering (Image from JNGSE web page). 


\section{International Journal of Science and Research (IJSR) \\ ISSN (Online): 2319-7064}

Index Copernicus Value (2015): 78.96 Impact Factor (2015): 6.391

\section{Conclusion}

This article highlights important facts that researchers should know about the Algerian scientific community and institutions. The intention of making publication and the targeted journals were discussed in this paper. In addition, ISI journals, IF and JCR were illustrated. Moreover, the steps toward writing scientific paper were described. Finally, the process of submitting a manuscript was reported in this article.

Further investigations on analyzing the situation of Algerian scientific community and institutions by describing the challenges and proposing the solutions are highly needed. Moreover, practical workshops on publication skills will contribute to the resolution of the challenges in scientific research in Algeria. The question of who is the responsible for the current negative performance of scientific research in Algeria must be answered and the problem should be resolved as the first step toward a bright future for scientific research in Algeria.

\section{Acknowledgment}

The author of the article would like to acknowledge Prof. Inas M. AlNashef from Masdar Institute of Science and Technology, Abu Dhabi, United Arab Emirates and Dr. Yacine Benguerba form Ferhat Abbas University of Setif, Algeria for their supports as advisors and collaborations as co-authors.

\section{References}

[1] Elsevier, (2009). "Guide for Authors." Entertainment Computing 1(1): I-V.

[2] (2016). "Algerian ranking universities " Retrieved 23/09/2016, 2016, from http://www.webometrics.info/en/africa/algeria.

[3] (2016. Retrieved 2016-09-27). "Thomson Corporation." from https://en.wikipedia.org/wiki/Thomson Corporation.

[4] Aissaoui, T. (2014). Studying abroad: Malysia T. Aissaoui. Malysia

[5] Aissaoui, T. (2016). Algerian scientific community and publication. T. Aissaoui. Algeria.

[6] Aissaoui, T. (2016). Skills of Writing a Scientific Article from Idea to Publication. Scientific Research Skills Series, Tamanghasset-ALGERIE, Laboratoire de Sciences et Environnement, Centre Universitaire de Tamanghasset-ALGERIE.

[7] Aissaoui, T., I. M. AlNashef and Y. Benguerba (2016). "Dehydration of natural gas using choline chloride based deep eutectic solvents: COSMO-RS prediction." Journal of Natural Gas Science and Engineering 30: 571-577.

[8] Cals, J. W. L. and D. Kotz (2013). "Effective writing and publishing scientific papers, part III: introduction." Journal of Clinical Epidemiology 66(7): 702.

[9] Cals, J. W. L. and D. Kotz (2013). "Effective writing and publishing scientific papers, part VI: discussion." Journal of Clinical Epidemiology 66(10): 1064.
[10]Day, R. A. (1983). How to Write and Publish a Scientific Paper. Philadelphia, ISI Press.

[11]Derntl, M. (2014). "Basics of research paper writing and publishing." Int. J. of Technology Enhanced Learning 6: 105-123.

[12] Ecarnot, F., M. F. Seronde, R. Chopard, F. Schiele and N. Meneveau (2015). "Writing a scientific article: A step-by-step guide for beginners." European Geriatric Medicine 6(6): 573-579.

[13]El-Omar, E. M. (2014). "How to publish a scientific manuscript in a high-impact journal." Advances in Digestive Medicine 1(4): 105-109.

[14] elsevier.com/authors. (2016). "UNDERSTANDING THE PUBLISHING PROCESS : How to publish in scholarly journals." from https://www.elsevier.com/ data/assets/pdf file/0003/91 173/Brochure_UPP_April2015.pdf.

[15]Hocine, K. (2004). "Scientific Research in Algeria Institutionalisation versus Professionalisation." Science Technology Society 9: 75.

[16] Kotz, D. and J. W. L. Cals (2013). "Effective writing and publishing scientific papers, part IV: methods." Journal of Clinical Epidemiology 66(8): 817.

[17] Kotz, D. and J. W. L. Cals (2013). "Effective writing and publishing scientific papers, part V: results." Journal of Clinical Epidemiology 66(9): 945.

[18] McVeigh, M. E. (2004). "Open Access Journals in the ISI Citation Databases: Analysis of Impact Factors and Citation Patterns A citation study from Thomson Scientific." Thomson Corporation.

[19] Moed, H. F. and T. N. Van Leeuwen (1995). "Improving the accuracy of institute for scientific information's journal impact factors." Journal of the American Society for Information Science 46(6): 461-467.

[20] O'Connor, M. C. a. P. (2009). Writing Scientific Research Articles Strategy and Steps. UK, A John Wiley \& Sons, Ltd., Publication.

[21] Online (1992). Thomson Corporation acquired ISI. Online, Retrieved 2016-09-27.

[22] Reuters. (2016. Retrieved 2016-09-28). "Thomson Reuters Corp (TRI.TO)." from http://www.reuters.com/finance/stocks/companyProfile?s ymbol=TRI.TO.

[23] Reuters, T. (2016). "Journal Citation Reports." Retrieved 09/22/2016, 2016, from http://thomsonreuters.com/en/productsservices/scholarly-scientific-research/researchmanagement-and-evaluation/journal-citationreports.html.

[24] Shokeir, A. A. (2014). "How to write a medical original article: Advice from an Editor." Arab Journal of Urology 12(1): 71-78.

[25] STEGMANN, J. (1999). "BUILDING A LIST OF JOURNALS WITH CONSTRUCTED IMPACT FACTORS." Journal of Documentation 55(3): 310-324.

[26] T. N. van Leeuwen, H. F. M., and J. Reedijk (1999). "Critical comments on Institute for Scientific Information impact factors: a sample of inorganic molecular chemistry journals." Journal of Information Science 25: 489-498. 
[27] Taborsky, M. (2007). "Impact factor statistics and publication practice: What can we learn?" Ethology 113(1): 1-8

[28] Valiela, I. (2001). Doing Science: Design, Analysis, and Communication of Scientific Research. New York, OXFORD UNIVERSITY PRESS.

[29] Waast, R. (2010). "Research in Arab Countries (North Africa and West Asia)." Science, Technology \& Society 15(2): 187-231.

Volume 6 Issue 1, January 2017

www.ijsr.net 